\title{
STOCHASTIC PHOSPHOROUS MODEL FOR ONONDAGA LAKE
}

\author{
Raymond P. Canale ${ }^{1}$ and Steven W. Effler ${ }^{2}$ \\ 'Department of Civil Engineering, University of Michigan, Ann Arbor, MI 48109-2125 and \\ ${ }^{2}$ Upstate Freshwater Institute, Syracuse, N.Y., U.S.A.
}

(First received June 1988; accepted in revised form February 1989)

\begin{abstract}
A probabilistic phosphorus model that utilizes the Monte Carlo technique was developed and applied to address water quality management issues for Onondaga Lake, N.Y. Several analyses were conducted to support model development: (1) evaluation of the loading and concentration of phosphorus in the lake; (2) determination of the natural variability of flow and non-point loading to the lake; (3) validation of a deterministic total phosphorus model for the lake; and (4) examination of the uncertainty associated with the phosphorus model using Monte Carlo techniques. Simulations with the probabilistic model have been used to evaluate the significance of year-to-year changes in rainfall, the level and variability of point sources, operation at METRO and uncertainty in the model coefficients. The results indicate that substantial reductions in loading from point sources and some control of non-point sources are necessary to achieve distinct improvements in water quality in the lake. Furthermore, significant year-to-year differences in phosphorus concentration are expected in the lake in response to natural variations in rainfall and runoff.
\end{abstract}

Key words-eutrophication, non-point phosphorus sources, stochastic modeling, phosphorus balance, water quality management, personal computer applications

\section{INTRODUCTION}

Deterministic models are widely used as tools to support lake water quality management activities. Phosphorus models are particularly important because of the central role this nutrient has in regulating phytoplankton biomass and related features of water quality. Deterministic models give a single value of concentration of phosphorus as a function of the value of input variables such as flow, loadings and model coefficients. This produces an unrealistic sense of reliability concerning the model predictions because models are not exact. In general, total phosphorus models have: (1) uncertainty associated with the identification of model coefficients and the mathematical representation of biochemical and physical processes; and (2) natural variations in model input functions such as tributary flow and non-point loadings.

It is critical from a water quality management perspective to have a quantitative understanding of the stochastic nature of model predictions to guide the decision-making process. This allows the user to determine the probability of attaining water quality goals as a function of the uncertainty of the model structure and the variability of environmental conditions.

A stochastic model has been developed with the capability to address these types of phosphorus management issues in Onondaga Lake, N.Y. This development requires: (1) an evaluation of the loadings and concentrations of phosphorus in the lake; (2) an analysis of the natural variability of flow and non-point loading to the lake; (3) validation of a deterministic total phosphorus model for the lake; and (4) calculation of the uncertainty associated with the model using Monte Carlo techniques.

\section{Onondaga Lake}

Onondaga Lake is located in the Finger Lakes region of central New York State $\left(43^{\circ} \mathrm{N}, 76^{\circ} \mathrm{W}\right)$, as shown in Fig. 1. The lake has a surface area of $11.7 \mathrm{~km}^{2}$, a mean depth of $12.0 \mathrm{~m}$ and a maximum depth of $20.5 \mathrm{~m}$. The major tributaries and the location of the discharge from the metropolitan sewage treatment plant (METRO) are also identified in Fig. 1. The lake empties into the Seneca River, which eventually flows into Lake Ontario. The lake flushing rates vary between 2.6 and 5.2 times/yr (Devan and Effler, 1983). The lake has received most of the domestic and industrial wastes from the Syracuse, N.Y. and its metropolitan area for the last $110 \mathrm{yr}$ and it is now hypereutrophic. Several manifestations of this condition, such as high populations of phytoplankton (Effler et al., 1981), low Secchi disc transparency (Devan and Effler, 1983) and extended periods of hypolimnetic anoxia (Effler et al., 1986) discourage recreational utilization of the lake.

\section{Loading}

Onondaga Lake, and its major tributaries have been monitored regularly since 1970 (Onondaga Country, 1985). The history of phosphorus loading and associated budgets for the lake have been described in detail previously (Devan and Effler, 

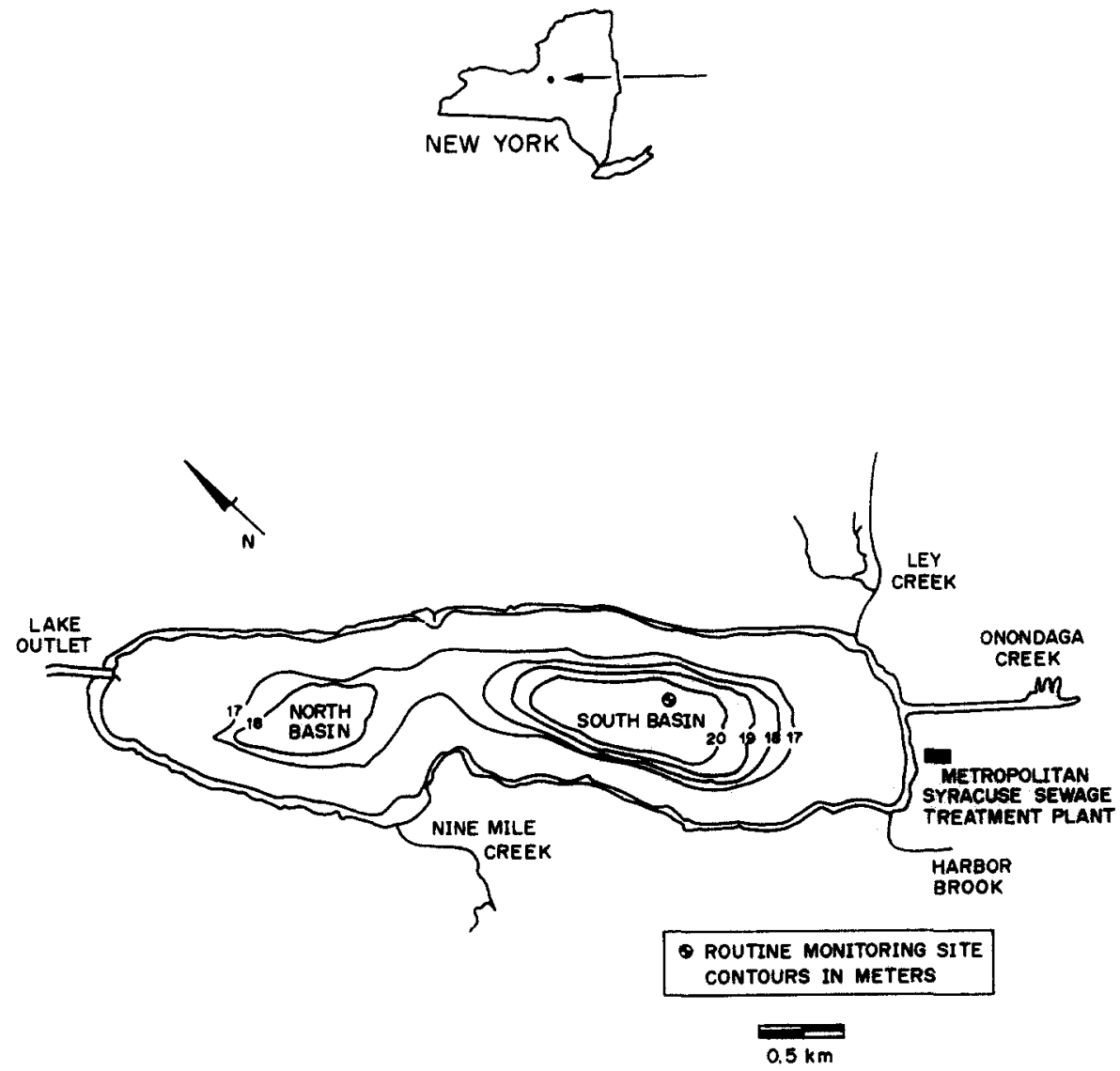

Fig. 1. Location of Onondaga Lake in New York State. Sources of phosphorus and lake bathymetry.

1983). An update of this analysis is presented in Fig. 2 for the period 1973-1985. Estimates are shown of the total load of phosphorus and the load from METRO alone.

Several efforts have been made to reduce the phosphorus loading to the lake. These have included: (1) legislation in July 1971 that banned the use of high-phosphorus detergents; (2) addition of secondary treatment at METRO in October 1979 and tertiary treatment in May 1981; and (3) improved maintenance of the sewer system. As a result, the total phosphorus load to the lake has decreased by about 65\% since 1973 (Fig. 2). This change in total loading reflects reductions in the input from METRO which currently has an effluent concentration of about $1 \mathrm{mg} \mathrm{l}^{-1}$ total phosphorus. However, despite improvements in treatment, METRO still contributes more than $70 \%$ of the total phosphorus load and the lake remains hypereutrophic.

Reductions in tributary phosphorus loading (total load minus METRO load in Fig. 2) have also occurred. However, these reductions in non-point loading are largely a manifestation of low rainfall and runoff in recent years. Figure 3 shows that tributary loading and tributary flow have a linear relationship with a correlation coefficient of 0.85 . Thus, it is important to consider the effects of natural variability in tributary flow on phosphorus concentrations in the lake, particularly if loadings from METRO are further reduced.

The statistical distribution of total annual flows from Onondaga Creek measured between 1952 and 1986 (U.S. Geological Survey, 1952-1986) is shown in Fig. 4. The distribution of these flows is approximately log-normal. This type of distribution also approximates the natural variability in the total annual tributary flow to the lake because the total flow is closely related to the Onondaga Creek flow (correlation coefficient $=0.96$ ). The average annual tributary flow from the Onondaga Lake drainage

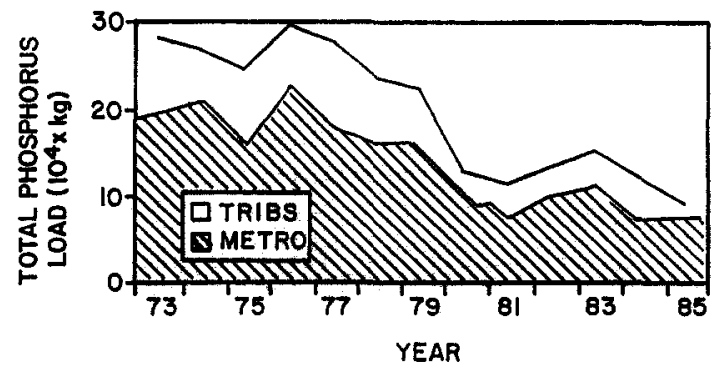

Fig. 2. Total phosphorus loading to Onondaga Lake. Tributary and METRO. 


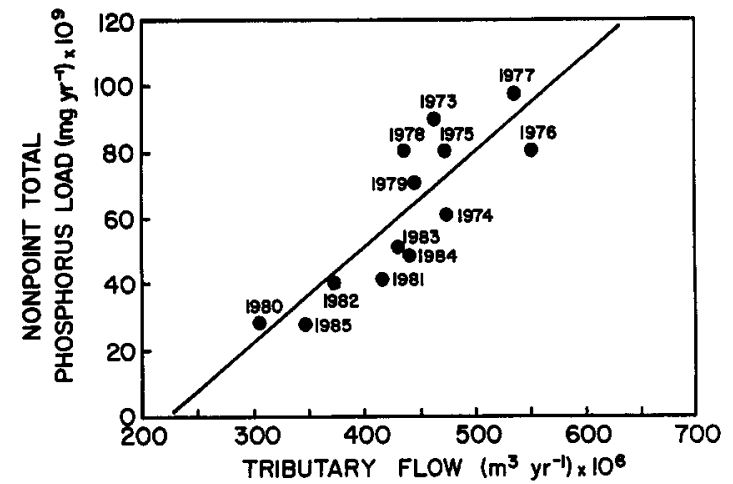

Fig. 3. Relationship between tributary flow and tributary phosphorus load to Onondaga Lake.

basin is $413 \times 10^{6} \mathrm{~m}^{3} \mathrm{yr}^{-1}$. The standard deviation of these annual flows is $85 \times 10^{6} \mathrm{~m}^{3} \mathrm{yr}^{-1}$.

\section{Lake phosphorus concentrations}

Total phosphorus concentrations were measured in the lake approximately twice per month from early April through late November since 1970 at a deep water location (Fig. 1). Water samples were collected at depths of $0,3,6,9,12,15$ and $18 \mathrm{~m}$ (Onondaga County, 1973-1986). Concentrations measured after spring turnover are commonly used to characterize lake conditions. However, this is impossible for Onondaga Lake because spring turnover failed to occur every year during the study period. This was a consequence of strong chemical density stratification of the water column caused by the discharge of large quantities of ionic waste into the lake (Effler and Perkins, 1987). Fall turnover does occur regularly. Therefore, lake phosphorus concentrations measured following turnover are used as an indicator of water quality and are plotted for different years as shown in Fig. 5. The summer average surface water total phosphorus concentrations in the lake are about one-half those observed after fall turnover.

The changes in concentrations roughly correspond to the changes in loading shown in Fig. 2. The lake concentrations measured following fall turnover have

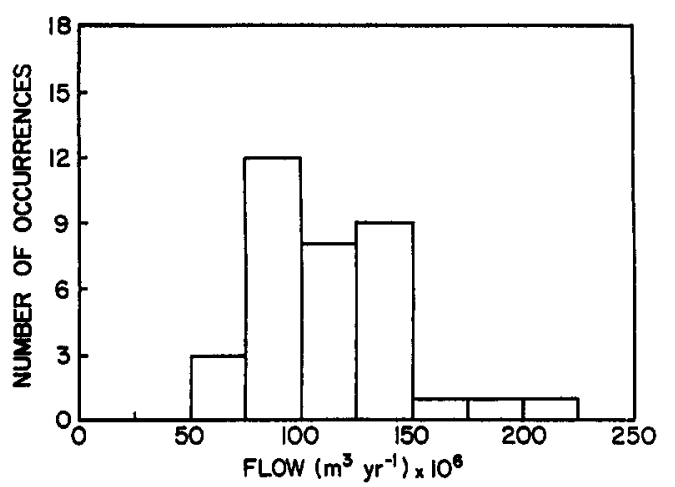

Fig. 4. Distribution of annual average flow rates for Onondaga Creek at Dorwin Avenue between 1952 and 1986.

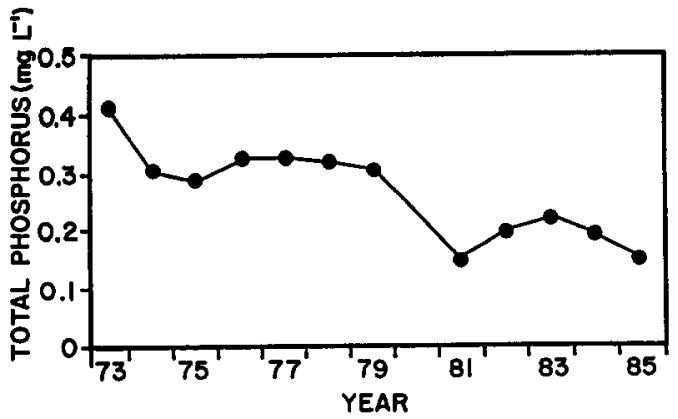

Fig. 5. Measured total phosphorus concentrations in Onondaga Lake following fall turnover.

decreased by more than $50 \%$ in response to decreases in external loading. The rapid response of concentrations to changes in loading is a result of the high flushing rate of the lake. Unfortunately phytoplankton biomass and transparency have remained essentially constant despite the changes in phosphorus concentration because the reductions have not been sufficient to significantly limit phytoplankton growth (Devan and Effler, 1983).

\section{MODELING}

\section{Deterministic model framework}

A number of phosphorus models have been developed for lakes that differ greatly in complexity with regard to the forms of phosphorus considered, the processes accommodated and the time and space scales utilized (Bowie et al., 1985). A total phosphorus model originally developed for the Great Lakes by Chapra and Reckhow (1983) has been selected for this study on Onondaga Lake. This model has been used extensively for management and long-term planning purposes because total phosphorus concentration is usually a reliable indicator of trophic state (Auer et al., 1986; Chapra and Dobson, 1981; Vollenweider, 1982). The model is described by the following equation:

$$
V \frac{\mathrm{d} C}{\mathrm{~d} t}=W-Q C-v A C,
$$

where $V$ is the volume of the lake $\left(\mathrm{m}^{3}\right), C$ is the concentration of total phosphorus ( $\left.\mathrm{mg} \mathrm{l}^{-1}\right), t$ is the time (yr), $W$ is the summation of annual point $\left(W_{\mathrm{P}}\right)$ and non-point $\left(W_{\mathrm{NP}}\right)$ loads $\left(\mathrm{g} \mathrm{yr}^{-1}\right), Q$ is the total annual flow into the lake from tributaries $\left(Q_{\mathrm{NP}}\right)$ and point sources $\left(Q_{\mathrm{P}}\right)\left(\mathrm{m}^{3} \mathrm{yr}^{-1}\right), v$ is the annual average net settling velocity of total phosphorus from the water column to the lake bottom $\left(\mathrm{m} \mathrm{yr}^{-1}\right)$ and $A$ is the bottom area of the lake $\left(\mathrm{m}^{2}\right)$. The net effects of all phosphorus kinetic and mass transfer processes in the lake are described by the coefficient $v$.

The steady-state solution of equation (1) is given by equation (2) for $C_{\mathrm{ss}}$ in terms of the point and 


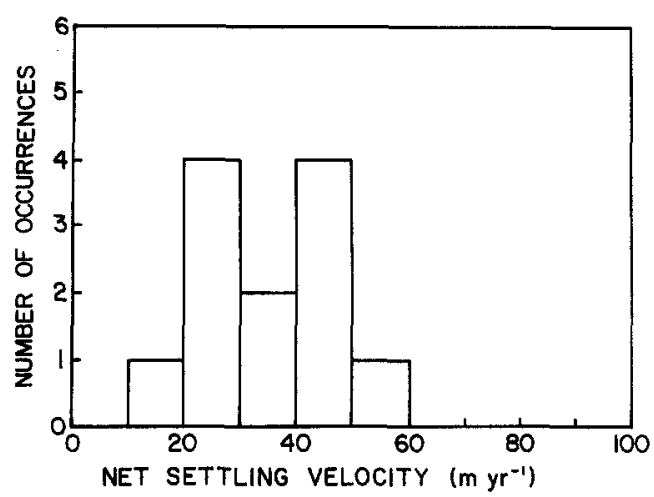

Fig. 6. Distribution of calculated annual average net settling velocities for Onondaga Lake for 1973-1985.

non-point components of $W$ and $Q$ :

$$
C_{\mathrm{ss}}=\frac{W_{\mathrm{NP}}+W_{\mathrm{P}}}{Q_{\mathrm{NP}}+Q_{\mathrm{P}}+v A} .
$$

This model framework, following appropriate validation can be used to predict the impact of future changes in phosphorus loading on lake concentrations. Furthermore, the framework is amenable to stochastic analyses aimed at evaluating the implications of model structure uncertainty and natural variations in environmental conditions on model predictions. The development and testing of more complex models for Onondaga Lake to simulate seasonal dynamics of phosphorus and phytoplankton (Canale et al., 1974; Thomann et al., 1975) awaits the execution of more extensive lake monitoring and laboratory studies to evaluate key model coefficients.

\section{Model validation}

Measured water quality data for Onondaga Lake can be used to directly estimate all the terms in equation (2) except the annual average net settling velocity. However, this coefficient can be calculated indirectly with equation (2) on a year-to-year basis for the period 1973-1985. The distribution of these calculated values is shown in Fig. 6. The distribution has a normal character, with a mean value of $34.1 \mathrm{~m} \mathrm{yr}^{-1}$ and $\mathrm{SD}=10.7 \mathrm{~m} \mathrm{yr}^{-1}$. The mean value is generally consistent with observations for other lakes with similar water quality (Chapra and Reckhow, 1983). No significant correlation occurs between $v$ and other model variables such as the flow into the lake. The magnitude of the year-to-year variations in $v$ observed for Onondaga Lake reflects limitations in the monitoring data and the model framework. The rather broad distribution suggests that it would be appropriate to consider the uncertainty associated with the settling velocity for water quality management purposes.

The average value of $v$, and individual flow and phosphorus loadings for each year have been used to calculate lake concentrations. The measured fall turnover total phosphorus concentrations and the

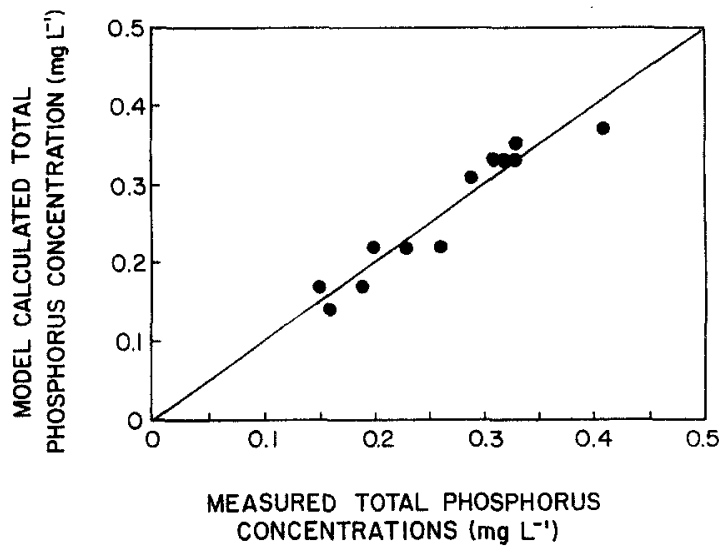

Fig. 7. Comparison between model calculated and measured total phosphorus concentrations in Onondaga Lake.

calculated values are shown in Fig. 7. The high level of correlation shows that the model can be used with an average value of $v$ to represent a wide range of water quality conditions in the lake.

\section{Stochastic model}

A stochastic total phosphorus model was developed for Onondaga Lake using the deterministic framework from equation (2) and Monte Carlo simulation techniques. This stochastic model performs repetitive calculations of total phosphorus while randomly changing values for flows, loadings and settling velocity. Each model simulation gives a single phosphorus concentration that depends on values from random number generators which are used to calculate the stochastic parameters. Similar Monte Carlo models have been developed for oxygen (Burges and Lettenmaier, 1975), toxic substances (Marr and Canale, 1989) and phytoplankton (Scavia et al., 1981).

The technique employed to model total phosphorus concentration in Onondaga Lake using Monte Carlo simulation procedures is illustrated in Fig. 8. The method can be used to investigate the implications of natural variations in flow and loading as well as uncertainty in the model representation of net settling. Distributions of total phosphorus concentrations produced by the Monte Carlo simulation procedures are illustrated separately.

Natural variability is computed using random selection of flows and loads. Values for $Q_{\mathrm{NP}}$ were taken from a log-normal distribution consistent with the historic flow data shown in Fig. 4. The associated value of $W_{\mathrm{NP}}$ was calculated using the linear expression developed to describe the functionality between $Q_{\mathrm{NP}}$ and $W_{\mathrm{NP}}$ shown in Fig. 3. The mean value of the point flow $\left(Q_{\mathrm{P}}\right)$ and point load $\left(W_{\mathrm{P}}\right)$ and their distributions depend on the design and operation of METRO. Various values were selected for the model input to test the significance of different conditions at METRO, in the future. Model uncertainty was 


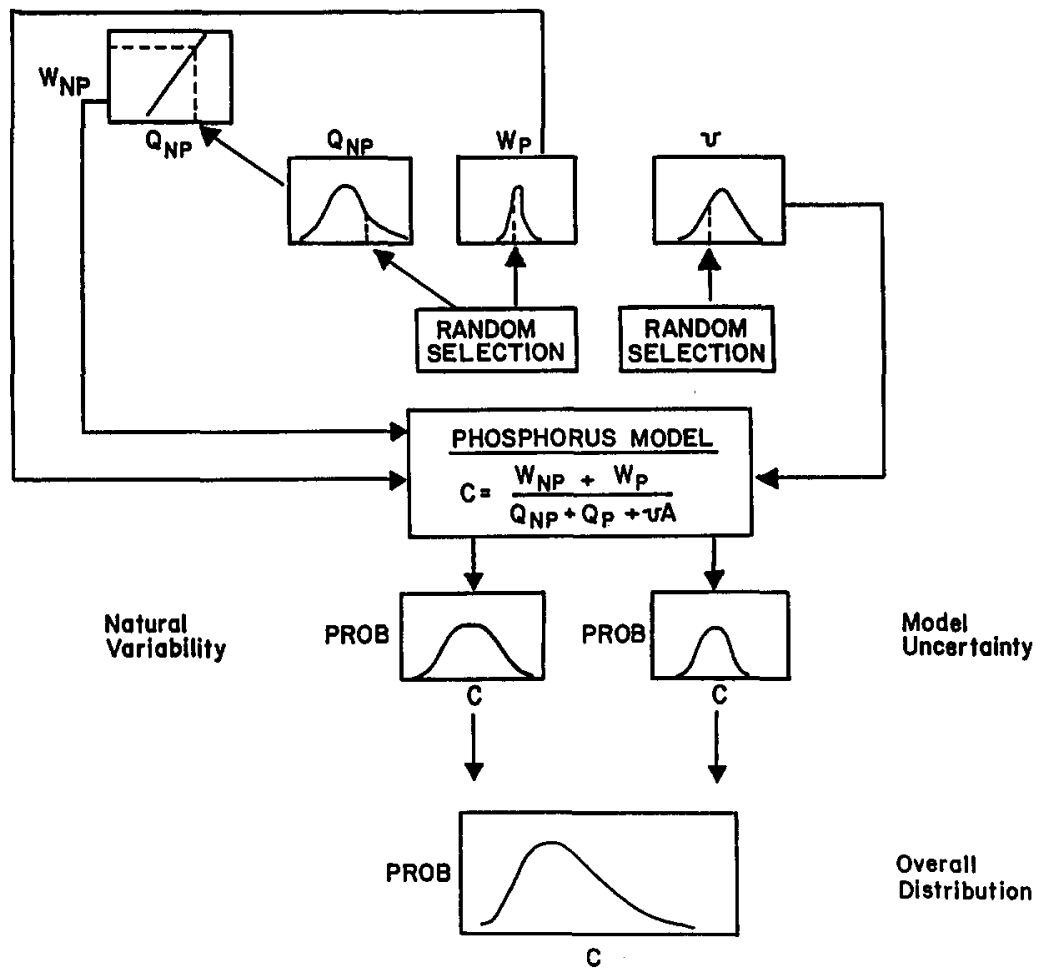

Fig. 8. Monte Carlo strategy for calculating model variability and uncertainty.

simulated using random selections of $v$ from the normal distribution shown in Fig. 6.

The stochastic model for total phosphorus in Onondaga Lake was expressed as an algorithm and implemented on an IBM-PC computer. Menus, interactive data entry tables, color graphics and animation were used to create a convenient and interesting computational environment. This is an important component of the software design because the model was developed to facilitate management applications. The advantages of the use of personal computers for similar problems have been described by Chapra and Canale (1987) and Canale and Auer (1987). Monte Carlo simulations were performed using 1000 random selections from the three stochastic distributions. Model runs required $<1 \mathrm{~min}$ of computation time for both calculations and display of results.

\section{MANAGEMENT APPLICATIONS}

Some applications of the model and the Monte Carlo technique are demonstrated here for selected cases that are expected to be of management interest. Water quality managers and regulators have not identified a total phosphorus goal for Onondaga Lake. Undoubtedly the goal will be based on the feasibility of controlling loadings and expected uses of the lake. A goal of $0.07 \mathrm{mg} \mathrm{1}^{-1}$ total phosphorus at fall turnover is assumed here. This corresponds to a summer average surface water concentration of approx. $0.035 \mathrm{mg} \mathrm{l}^{-1}$. This concentration has been associated with mesotrophy elsewhere (Auer et al., 1986; Vollenweider, 1982). Thus, this magnitude of reduction in phosphorus concentration would be expected to be accompanied by distinct improvements in related features of water quality, such as reduced phytoplankton biomass, increased transparency and improved hypolimnetic oxygen resources.

The METRO effluent currently contains about $1.0 \mathrm{mg}^{-1}$ total phosphorus and has a flow of approx. $75 \times 10^{6} \mathrm{~m}^{3} \mathrm{yr}^{-1}$. The stochastic model predicts an average fall turnover concentration of $0.18 \mathrm{mg} \mathrm{l}^{-1}$ in Onondaga Lake for this point source loading. The concentration distribution is shown in Fig. 9(d). This distribution reflects the overall impact of uncertainty in the settling velocity and variability in rainfall and point loading. The likelihood of attaining the $0.07 \mathrm{mg}^{-1}$ goal under these loading conditions is essentially zero.

The individual components that contribute to the uncertainty are also presented in Fig. 9(a-d). The variability in the lake concentration caused by normally distributed point loads at METRO with $\mathrm{SD}=0.10 \mathrm{mg} \mathrm{l}^{-1}$ is shown in Fig. 9(a). Under these conditions greater variability in lake concentration is caused by non-point loads [Fig. 9(b)]. Note that the stochastic model provides the water quality manager the opportunity to test the significance of more or less consistent operations at METRO. The effect of the uncertainty associated with the model represenation of net settling is presented in Fig. 9(c). It is seen that 

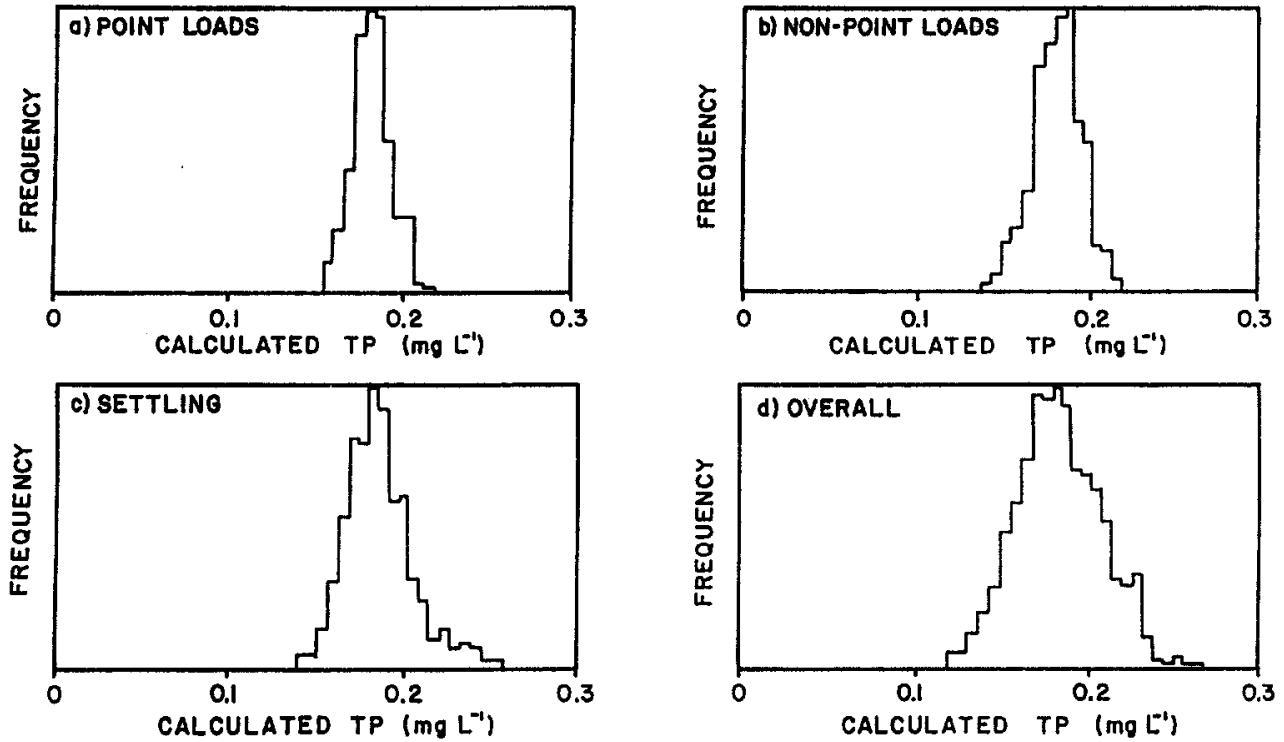

Fig. 9. Monte Carlo simulations for model uncertainty and variability during an average flow year with a METRO effluent concentration of $1.0 \mathrm{mg} \mathrm{l}^{-1}$ : (a) variation due to point loads alone; (b) variation due to non-point loads alone; (c) uncertainty due to model coefficient for settling; (d) overall affect of variability and uncertainty.

significant reduction in the overall uncertainty of model predictions may be achieved through more precise identification of the processes that affect phosphorus cycling in the lake.

The average lake concentration at fall turnover can be reduced to $0.09 \mathrm{mg} \mathrm{1}^{-1}$, and the goal attained with $23 \%$ probability, if the METRO effluent concentration is reduced to a level of $0.1 \mathrm{mg} \mathrm{l}^{-1}$. The resultant distribution is shown in Fig. 10. However, during wet years the lake concentrations are expected to be higher than during dry years. For example, at the reduced METRO effluent concentration $\left(0.1 \mathrm{mg} \mathrm{1}^{-1}\right)$ during a dry year (with $Q_{\mathrm{NP}}=350 \times 10^{6} \mathrm{~m}^{3} \mathrm{yr}^{-1}$ ) the average concentration at fall turnover is predicted to be $0.07 \mathrm{mg} \mathrm{I}^{-1}$ and there is a $33 \%$ probability of achieving the goal. However, with the same high level of treatment at METRO during a wet year (with $Q_{\mathrm{NP}}=550 \times 10^{6} \mathrm{~m}^{3} \mathrm{yr}^{-1}$ ) the average concentration at fall turnover is increased to $0.12 \mathrm{mg} \mathrm{l}^{-1}$ and the probability of achieving the $0.07 \mathrm{mg}^{-1}$ goal is zero. Clearly significant differences in water quality in the lake are expected for wet compared to dry years to the extent that the benefit of increased treatment at METRO may be undermined during high runoff years.

Given these circumstances, it is appropriate to use the model to calculate the expected lake concentration of total phosphorus if the METRO effluent is completely diverted around the lake. For this situation the average concentration at fall turnover is $0.08 \mathrm{mg} \mathrm{l}^{-1}$ and the probability of attaining the water quality goal is increased to $27 \%$. Thus, the model indicates that some control of non-point sources of phosphorus may be necessary to attain high levels of water quality.
The combined effects of management efforts directed at both METRO and non-points sources can be evaluated with the model. For example, it is possible to evaluate the potential benefits of reducing the runoff flows and their variability by a factor of one-third, assuming that the concentration at METRO is $0.1 \mathrm{mg} \mathrm{l}^{-1}$. This level of reduction in non-point loading is hypothetical because a comprehensive analysis of land-use patterns and their relationship to non-point loading has not been conducted for the lake watershed. However, under these assumed conditions it is predicted that the average phosphorus concentration at fall turnover would be $0.04 \mathrm{mg}^{-1}$, and the water quality goal of $0.07 \mathrm{mg}^{-1}$ would be attained with $89 \%$ probability.

An important limitation of all the above analyses is that the average value of net settling velocity was

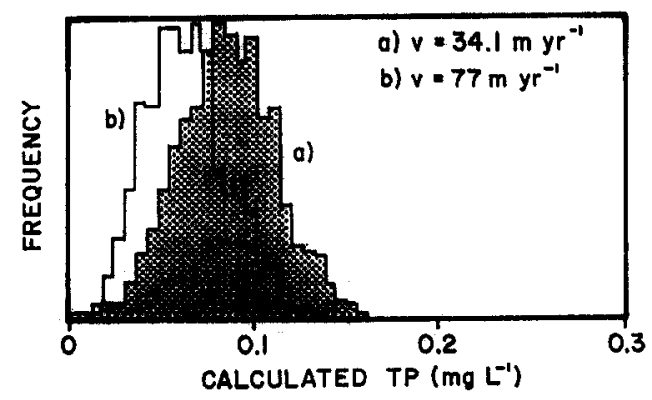

Fig. 10. Monte Carlo simulations of average lake phosphorus with METRO at $0.10 \mathrm{mg} \mathrm{l}^{-1}$ and no control of non-point sources for two different values of $v$, the model validation value $\left(v=34.1 \mathrm{~m} \mathrm{yr}^{-1}\right)$ and a higher value $\left(v=77 \mathrm{~m} \mathrm{yr}^{-1}\right)$ that characterize oxic hypolimnetic conditions. 
considered independent of the level of phosphorus loading. Many studies have suggested that as phosphorus loading decreases apparent net settling velocities increase, resulting in increased retention of phosphorus in the sediments. If reductions of phosphorus loading are sufficient to decrease the period of anoxia or eliminate it entirely, phosphorus retention can increase substantially. For example, Nurnberg (1984) found that the average phosphorus retention for anoxic lakes was $33 \%$ compared to $52 \%$ for oxic lakes. This is equivalent to increasing the net settling velocity in Onondaga Lake from 34.1 to about $77 \mathrm{~m} \mathrm{yr}^{-1}$. The higher velocity was used to calculate the concentration of phosphorus for an average rainfall year with METRO effluent at $0.1 \mathrm{mg} \mathrm{1}^{-1}$ and no reduction of non-point loads or flow (see Fig. 10). The average concentration is reduced to $0.06 \mathrm{mg} \mathrm{l}^{-1}$ with a $56 \%$ probability of meeting the $0.07 \mathrm{mg} \mathrm{l}^{-1}$ objective. This is more than double the probability of achieving the objective compared to a similar calculation with no adjustment of the net settling velocity. This analysis clearly points to the need to couple the water column model to a model for phosphorus exchange with the sediment as performed by Lung et al. (1976) as well as others. Appropriate experimental work to support such model development is underway for Onondaga Lake.

\section{CONCLUSION}

A stochastic total phosphorus model has been developed for Onondaga Lake that utilizes the Monte Carlo technique and a deterministic phosphorus model as the analytical framework. Measured loads and lake total phosphorus concentrations were used to test the phosphorus model. A reduction in phosphorus loading to the lake by a $65 \%$, and a $50 \%$ reduction in lake phosphorus concentration, have been observed between 1973-1985 as a result of reclamation efforts. The deterministic phosphorus model was developed to describe the changes in lake phosphorus concentration for this period. The stochastic model accommodates the influence of both model uncertainty and natural variations in nonpoint and point loadings of phosphorus to the lake. Statistical distributions necessary to support the Monte Carlo analyses were established through the analysis of historic tributary flow data and an evaluation of the functionality between non-point loading and tributary flow. Calculations with the stochastic phosphorus model indicate that significant year-toyear differences in lake phosphorus concentrations can be expected in response to natural variations in rainfall and runoff. Further, it appears likely that substantial reductions or complete removal of loading from METRO and some control of nonpoint sources of phosphorus are necessary to achieve distinctly mesotrophic conditions in Onondaga Lake. Finally, model simulations suggest that the accuracy of such predictions could be improved by using more accurate estimates of net settling and phosphorus exchange with the sediments as a function of phosphorus loading.

Acknowledgements-This work was supported by the Onondaga County Department of Drainage and Sanitation and the Onondaga County Management Council. This is contribution No. 90 of the Upstate Freshwater Institute.

\section{REFERENCES}

Auer M. T., Kieser M. S. and Canale R. P. (1986) Identification of critical nutrient levels through field verification of models for phosphorus and phytoplankton growth. Can. J. Fish. aquat. Sci. 43, 379-388.

Bowie G. L., Mills W. B., Porcella D. B., Campbell C. L., Pagenkopf J. R., Rupp G. L., Johnson K. M., Chan P. W. H., Gherini S. A. and Chamberlain C. E. (1985) Rates, Constants and Kinetic Formulations in Surface Water Quality Modeling, 2nd edition. U.S. Environmental Protection Agency, Athens, Ga.

Burges S. J. and Lettenmaier D. P. (1975) Probabilistic methods in steam quality management. Wat. Resour. Bull. 7, 115-130.

Canale R. P. and Auer M. T. (1987) Personal computers and environmental engineering-Part II. Applications. Envir. Sci. Technol. 21, 936-942.

Canale R. P., Hineman D. F. and Nachippan S. (1974) A biological production model for Grand Traverse Bay. Technical Report No. 37, Sea Grant Program, Univ. of Michigan, Ann Arbor, Mich.

Chapra S. C. and Dobson H. F. H. (1981) Quantification of the lake typologies of Naumann (surface growth) and Thienemann (oxygen) with special reference to the Great Lakes. J. Great Lakes Res. 7, 182-193.

Chapra S. C. and Canale R. P. (1987) Personal computers and environmental engineering-Part I. Trends and perspectives. Envir. Sci. Technol. 21, 832-837.

Chapra S. C. and Reckhow K. H. (1983) Engineering Approaches for Lake Management; Vol. 2: Mechanistic Modeling. Butterworth, Boston, Mass.

Devan S. P. and Effler S. W. (1983) History of phosphorus loading to Onondaga Lake. J. envir. Engng Div. ASCE 110, 93-109.

Effler S. W. and Perkins M. G. (1987) Failure of spring turnover to occur in Onondaga Lake, N.Y., U.S.A. Wat. Air. Soil. Pollut. 34, 285-291.

Effler S. W., Field S. D., Mayer M. A. and Sze P. (1981) Response of Onondaga Lake to restoration efforts. J. envir. Engng Div. ASCE 107, 191-210.

Effler S. W., Perkins M. G. and Brooks C. M. (1986) The oxygen resources of the hypolimnion of ionically enriched Onondaga Lake, N.Y., U.S.A. Wat. Air Soil Pollut. 29, 93-108.

Lung W. S., Canale R. P. and Freedman P. L. (1976) Phosphorus models for eutrophic lakes. Wat. Res. 10, 1101-1114.

Marr J. K. and Canale R. P. (1989) Load allocations for toxics using the Monte Carlo method. J. Wat. Pollut. Control Fed. In press.

Nurnberg G. K. (1984) The prediction of internal phosphorus load in lakes with anoxic hypolimnia. Limnol. Oceanogr. 29, 111-124.

Onondaga County (1973-1986) Onondaga Lake Monitoring Program. Annual publication, Onondaga County, Syracuse, N.Y.

Scavia D., Powers W. F., Canale R. P. and Moody J. L. (1981) Comparison of first-order error analysis and Monte Carlo simulation in time-dependent lake eutrophication models. Wat. Resour. Res. 17, 1051-1059. Thomann R. V., DiToro D. M., Winfield R. P. and O'Connor D. J. (1975) Mathematical modeling of 
phytoplankton in Lake Ontario, 1. Model development and verification. Report EPA-660/3-75-005. U.S. Environmental Protection Agency Office of Research and Development, Corvalis, Oreg.

U.S. Geological Survey (1952-1986) Water Resources Data for New York, Water Years 1952-1986, Western New York. Albany, N.Y.

Vollenweider R. A. (Ed.) (1982) Eutrophication of Waters: Monitoring, Assessment and Control. Organization for Economic Cooperation and Development, Paris. 